\title{
SÁNG TẠO NGHỆ THUẬT CỦA W. SHAKESPEARE TRONG BỐI CẢNH VĂN HÓA PHỤC HƯNG
}

\author{
Artistic creativities of $W$. Shakespeare in the context of Renaissant culture
}

Ngày nhận bài: 13/9/2016; ngày phản biện: 18/9/2016; ngày duyệt đăng: 21/11/2016

\section{Lê Nguyên Cẩn*}

\section{TÓM TẮT}

Gắn liền với bối cảnh văn hóa Phục hưng, các sáng tạo nghệ thuật của Shakespeare mang được sức sống của thời đại đó, thể hiện qua nghệ thuật điển hình hóa đặc sắc, qua đề tài về tình yêu, về cuộc đấu tranh giữa cái Thiện và cái Ác, giữa Tình yêu và Thù hận, giữa cái Mới đang hình thành và khẳng định với cái $C$ ũ đang chết đi nhưng vẫn cố bám lấy cuộc đời, giữa hai bản ngã trong một bản ngã theo góc nhìn phân tâm học. Các nhân vật chính đều đạt mức độ điển hình, kết tinh thành siêu mẫu - archetype - thể hiện được qui luật vận động của lịch sử. Nhân vật vì̀a mang tầm rộng của hiện thực đời sống, vưa có chiều sâu tâm lí. Nghệ thuật điển hình hóa trong sáng tạo của Shakespeare là tạo ra tất cả trong một và một trong tất cả, là tạo ra tiếng cười theo nguyên tắc trần tục hóa cái thiêng liêng và thiêng liêng hóa cái trần tục, là mở rộng giới hạn của hiện thực theo chiều dài thời gian và chiều rộng của không gian, để qua đó ông khẳng định các giá trị người của con người, khẳng định các giá trị nhân văn của thời đại Phục hưng.

Từ khóa: Phuc hung; Shakespeare; nghệ thuật điển hình hóa; phân tâm học; tiếng cuời carnavale

\section{ABSTRACT}

Together with cultural context of Renaissance, the artistic creativities of Shakespeare bring vitality of that era as shown by the uniquetypification, through love theme and war, between the Good and evil, love and hate, the New growing and the Old dying or between two egos inside an ego under psychoanalytical perspective. The main characters archive to supermodel -archetype and express the moving of history. Characters are combined both wide-range of realistic life and psychological depth. The typification of Shakespeare's merchandise is a creation of all in one and one in all. Laugh is created on the secularization of sacred and the deification of normal, is an expansion of the limitation of realityin accordance with the length of time and the width of the space. Based on that, he affirmed human values under Renaissance era.

Keywords: Renaissance; Shakespeare; typification; psychoanalysis; laughter carnavale

Đã bốn thế kỉ trôi qua, kể từ ngày 23/4/1616 - ngày thiên tài W. Shakespeare đi vào cõi bất tử, bản tình ca Romeo and Juliet của ông vẫn không ngừng vang lên cổ vũ cho tình yêu đôi lứa, cho khát vọng hạnh phúc, bình yên và câu hỏi tự vấn to be or not to be mà Hamlet đưa ra trong vở bi kịch cùng tên vẫn mãi mãi là câu hỏi mở hướng tìm đường cho mỗi con người, mỗi dân tộc trên hành trình lịch sử của nó. Các sáng tạo nghệ thuật vô giá mà ông để lại trở thành di sản văn học quý báu của nhân loại, di sản đó cũng là ánh xạ của sự kết tinh văn hóa mang đậm tính chất nhân văn thời đại Phục hưng.

\footnotetext{
*Phó Giáo sư, Tiến sĩ - Khoa Ngữ Văn, Đại học Sư phạm Hà Nội
} 
Nói đến văn hóa Phục hưng là nói đến thời kì lịch sử đặc biệt, bước ngoặt vĩ đại trong lịch sử châu Âu và nhân loại, là thời đại khổng lồ đã sản sinh những con người khổng lồ đa dạng về các giá trị văn hóa, trong đó giá trị văn hóa lớn nhất là chủ nghĩa nhân văn, lấy việc đề cao con người để khẳng định các giá trị người trong con người, để khẳng định phẩm chất nhân tính của con người trần thế. Con người vừa là kết tinh cao nhất của sự hoàn thiện về cơ thể sinh học, vừa là sự viên mãn về mặt tinh thần như Hamlet ca ngợi: "Kì diệu thay là con người! Con người cao quý làm sao về mặt lí trí, vô tận làm sao về mặt năng khiếu! Hình dung và dáng điệu mới giàu ý nghĩa và đáng kính làm sao! Trong hành động thật như thần tiên, về trí tuệ ngang tài Thượng đế! Thật là vẻ đẹp của thế gian, kiểu mẫu của muôn loài!"

[4, tr.211].

Giá trị người gắn liền với khả năng lí giải hiện thực và năng lực hành động để cải biến hiện thực được nhận thức đó, là sự gạt bỏ quan niệm "tội lỗi tổ tông" để hòa đồng với thế giới xung quanh, tắm mình trong đại tự nhiên bát ngát màu xanh. Giá trị tự do mà tự thân mỗi người đều có, vốn là di sản tinh thần Hi Lạp để lại, được con người thời đại Phục hưng tiếp thu và đề cao, ở đó con người ý thức được bản thân nó có sẵn phẩm chất tự do và cần phải phát huy sức mạnh của tự do trong mỗi hành động để minh chứng cho sức sống, cho sự trường tồn của chính nó. Việc nhận thức giá trị tự do đã nâng Hamlet lên tầm cao đặc biệt: Hamlet trở thành người mở đường trong bước ngoặt lịch sử. Hamlet chỉ ra "cả thế giới là một nhà tù mà Đan Mạch là nhà tù ghê tởm nhất", chỉ ra sự thật phũ phàng "cứ hàng vạn người mới có một người lương thiện" [4; tr.208], chỉ ra cái ác đang thống trị cái thiện. Tỷ lệ mà Hamlet đưa ra là một tỷ lệ kinh hoàng, cho thấy sự xuống cấp của các thang bậc giá trị nhân phẩm, cho thấy cái ác tràn lan gắn với sự bùng nổ của chủ nghĩa cá nhân ích kỉ, của chủ nghĩa hư vô tuyệt đối. Nhưng nhận thức của Hamlet không phải là Hamlet phải làm cái gì mà Hamlet phải thực hiện công việc đó như thế nào, nói cách khác nhận thức về tự do là nhận thức về qui luật hành động, về cách thức hành động. Đây cũng chính là vấn đề điển hình trong nghệ thuật. Nếu Hamlet giết Clodius khi hắn đang cầu nguyện sau khi xem vở kịch lấy lại câu chuyện Gandagô, hoàng thân của nước Italia bị kẻ thù giết hại bằng cách đổ thuốc độc vào tai năm 1538 , thì dư luận xã hội sẽ cho rằng Hamlet giả điên để giết chú vì ngai vàng quyền lực và như vậy giá trị của vở kịch không lớn, vì mô típ trả thù kiểu đó vốn đầy rẫy trong văn chương kiếm hiệp mọi thời. Đương nhiên, sau khi vở kịch "Vụ mưu sát Gôndagô" diễn xong thì chân tướng kẻ thù đã lộ ra nhưng cũng chỉ có hai người biết điều đó, một là kẻ sát nhân Clodius, hai là Hamlet. Hamlet muốn đưa kẻ sát nhân đó ra trước vành móng ngựa, bắt hắn phải thú nhận mọi tội ác ghê tởm. Vì thế, sự trả thù ở đây không phải là trả thù cho một cá nhân, cho dù đó là điểm xuất phát, mà đây là sự trả thù cho một thời đại ở đó các giá trị nhân văn bị xóa bỏ, là phục hưng lại công lý chính nghĩa. Hamlet được sinh ra là “để dẹp yên mọi sự bất bằng"[4; tr.194], là con người mà thời đại Phục hưng cần đến để thực hiện mục tiêu và lí tưởng của chủ nghĩa nhân văn. Cũng trong ý nghĩa đó, Othello, trong vở kịch cùng tên, đi tới quyết định tự tay mình giết chết Desdemona. Othello lập luận: "Nhưng nàng phải chết, nếu không nàng sẽ còn lừa dối những người khác nữa. Hãy tắt ngọn đèn kia rồi tắt ngọn đèn này..."[4; tr.448]. Hành động của Othello xảy ra khi Othello rơi vào cạm bẫy của Iago, khi Othello tin rằng niềm tin mà chàng đặt vào Desdemona đã bị phản bội, đã bị lừa dối và khi một con người trung thực như Othello bị tước mất niềm tin vào cuộc sống thì hành động của nhân vật sẽ mang tính chất cực đoan, không thể ngăn chặn để đến khi sự thực được phơi bày thì nhân vật mới lấy lại được niềm tin đã mất. Các nhân vật như Hamlet hay Othello đều mang trong mình khát vọng ánh sáng, khát vọng hoàn thiện con người, tôn vinh 
con người và luôn thể hiện những khát vọng đó bằng hành động cụ thể.

Các nhân vật được Shakespeare nhấn mạnh qua tiêu đề mỗi vở kịch hay các nhân vật khác được đặt trong quan hệ với nhân vật chính đều đạt mức độ điển hình, kết tinh thành siêu mẫu - archetype - thể hiện được qui luật vận động của lịch sử. Tính điển hình không phải chỉ là việc tạo ra nhân vật chưa hề có mà là tạo ra kiểu nhân vật vì̀a mang tầm rộng của hiện thực đời sống, để mỗi độc giả hay khán giả khi đọc khi xem biểu diễn đều nhận ra bóng dáng thời đại mình trong đó, vừa có chiều sâu tâm lí, chiều sâu tạo ra bản sắc cá nhân để nhân vật đó không bị hòa lẫn với bất cứ ai hay bị tan biến ở bất cứ chỗ nào. Nhân vật điển hình, do đó, bề ngoài mang dáng vẻ của điêu khắc, hội họa, còn bên trong là cả một thế giới của trầm tư triết học, với những diễn biến nội tâm phức tạp thường dẫn tới các khả biến văn chương tùy thuộc cách thức xử lí của mỗi nhà văn. Nhân vật điển hình trong văn học chính là kiểu hòa quyện tất cả trong một và một trong tất cả. Chẳng hạn, Shakespeare không xây dựng vở Othello theo kiểu chuyện tình tay ba, kiểu truyện khá phổ biến trong văn chương thế giới, mà xây dựng theo nguyên tắc điển hình hóa khi tái hiện các xung đột xã hội phức tạp nhiều chiều, vừa có bề nổi vừa có bề sâu, vừa có xung đột màu da sắc tộc vừa có xung đột đạo lí giữa tài năng đức độ và sự hèn kém bản năng. Nhân vật Iago, trong vở kịch này, được xây dựng theo nguyên tắc đó, trở thành đại biểu cho hạng người theo chủ nghĩa hư vô cuồng tín. Iago căm thù Othello vì Othello là người da đen mà lại có tài năng thực sự. Dưới con mắt Iago, một người da đen không thể có những phẩm chất đó, cho nên nhiệm vụ của Iago là phải loại bỏ Othello; Iago căm thù Desdemona vì Desdemona đẹp, bởi trong mắt hắn thế giới không tồn tại cái đẹp hay các giá trị đẹp, đối với Iago thế giới là phi nhân tính, là hư vô, là xã hội phi giá trị hay xã hội phi xã hội. Iago căm thù cái tài, cái đẹp và khi hắn phủ nhận các giá trị nhân tính cũng chính hắn phủ nhận con người. Đối lập với Iago, hành động tự trừng phạt mình của Othello cũng chính là hành động khẳng định lại các giá trị người của con người, cho thấy một khả biến, đó là con người khi nhận ra sai lầm, cho dù ở mức độ nào, thì con người cũng có đủ dũng cảm để sửa chữa cái sai lầm ấy. Cái chết của Othello là sự chuộc tội và cũng chính là sự nhận thức giá trị con người, bởi lẽ Othello bị đặt đối đầu với hạng người phi nhân tính, hư vô chủ nghĩa.

Các nhân vật khác như Macbeth, kiểu con người có thể chất khỏe mạnh nhưng bị dẫn dắt bởi những tham vọng ngông cuồng theo cách leo cao luồn sâu, đạp đổ bằng mọi thủ đoạn, triệt tiêu đối thủ một cách không thương tiếc để đứng trên đầu người khác, để leo lên đỉnh cao tột cùng của quyền lực..., hay King Lear, kiểu người tự mãn, kiêu ngạo khôn cùng, với những ham muốn cá nhân quái đản không theo một qui luật nào, đã biến mọi giá trị văn hóa thời đại thành những phần quà ban phát theo tính chất của trò chơi mà ông ta theo đuổi, đem đất nước ban phát cho những kẻ tội đồ, khen thưởng cho những kẻ đạo đức giả, xưng tụng tán dương những kẻ ăn bám vô công rồi nghề, loại bỏ lương tri, xua đuổi tình người, biến vị tha thành vị kỉ... cũng đều là những điển hình cho những hạng người trong xã hội lúc đó, xã hội của những vũ điệu hóa trang, của lễ hội carnavale vừa trên sân khấu, vừa trong hội diễn, vừa trong bản thân cuộc đời hiểu theo cách nói mà Shakespeare đặt vào cửa miệng Antonio trong vở The Merchant of Venice: "tôi nhận thức cuộc đời này đúng thực chất của nó, Graxyanô ạ, nó là một cuộc hý trường, ở đó mỗi người phải sắm một vai trò. Vai trò của tôi là một vai trò buồn bã" [3; tr.96]. Thế giới là một hý trường - cuộc đời là một sân khấu hay như cách nói của Balzac: xã hội là một Tấn trò đời, chính là sự phát hiện ra qui luật vận động của lịch sử, đã qui định sự khác biệt giữa Shakespeare với những người cùng thời. Những người cùng thời với Shakespeare chỉ đưa lại những câu chuyện, có 
thể thương tâm, có thể nhạt nhẽo vô vị, có thể mua vui giải trí tùy lúc tùy người, nhưng đều không đạt tới chiều sâu của vận động lịch sử, của sự chuyển hóa âm thầm nhưng chắc chắn của các lực lượng xã hội mới trong lòng xã hội nửa phong kiến nửa giáo hội, tạo ra những vết rạn nứt không thể hàn gắn trong xã hội quân quyền và thần quyền. Các nhân vật như Romeo, Juliet, Hamlet, King Lear, Macbeth, Othello; Desdemona, Shylock, Antonio, Bassanio, Timon, Antony, Cleopatra, Julius Ceasar,... đều điển hình cho những trạng huống hay hoàn cảnh, tạo thành các điểm nhấn đặc biệt trên sân khấu hý kịch hay tấn tuồng nhân loại của thời đại Phục hưng, nơi các mâu thuẫn xã hội đối đầu hoặc lộ diện hoặc ẩn khuất đang diễn ra theo qui luật phát triển vận động tự thân của thời đại.

Nhưng nếu chỉ dừng ở cấp độ đã nêu thì tính điển hình cũng chỉ phản ánh được cái "kì diệu thay là con người", mà chưa đạt tới "con người là kiểu mẫu của muôn loài và vạn vật". Skakespeare đã thực hiện được điều khó khăn thứ hai này bằng cách tạo ra kiểu nhân vật phân thân, nhân vật vừa là nó vừa không phải là nó, kiểu nhân vật đặc trưng cho thời kì lịch sử đi vào chỗ ngã năm ngã bảy..., tại đó con người chỉ biết dựa vào chính nó để trả lời mọi vấn đề mà thời đại đặt ra. Bản chất của câu hỏi tự vấn to be or not to be cũng gắn chặt với bối cảnh văn hóa đặc trưng này. Tính chất lưỡng phân đó cho phép nghiên cứu kiểu nhân vật của ông trên bình diện phân tâm học, cho thấy kiểu nhân vật đa dạng về tâm lí, có biểu hiện nhiều mặt về tính cách. Chẳng hạn, nếu Hamlet chấp nhận việc mẹ tái giá với chú ruột ngay sau khi cha chết như là một việc đã rồi, thì ngai vàng quyền lực sẽ thuộc anh ta là chuyện không phải bàn. Nhưng Hamlet hành động có phải vì ngai vàng quyền lực không hay còn có điều gì hơn thế nữa? Phải chăng, Hamlet mang trong mình "mặc cảm Oedipe", như một đặc tính phổ quát của nhân loại và càng phổ quát thì tính điển hình càng cao. Nhân vật King Lear là điên thật vì bệnh lí hay điên rồ vì ngạo mạn; nhân vật Macbeth với sở thích ngông cuồng, luôn thích thú ngắm nhìn đối thủ chết trong đau đớn, phải chăng là kiểu loại của masochisme hay hậu duệ của sadisme? Giữa Hamlet và Don Quichotte phải chẳng chỉ hoàn toàn là khác biệt? Trong bài "Dostoievski và tội giết cha", in trong cuốn Các tiểu luận về phân tâm học ứng dụng, Freud đã khẳng định ba kiệt tác văn chương của mọi thời: Oedip - Vua của Sophocle, Hamlet của Shakespeare và Anh em nhà Karramazov của Dostoievski đều luận giải môtip mang tính chất Oedip liên quan đến tội giết cha [2;139]. Trong thực tiễn, kiểu con người lưỡng phân đó là hiện thân của kiểu nhân vật đi tìm lại chính mình, trở về với bản ngã của mình, tức là tìm về với các giá trị tự thân vĩnh hằng của con người nói chung. Đây cũng là đặc trưng lưỡng tính của văn hóa Phục hưng, trong bối cảnh tại đó những tài năng mới đang được hoài thai hoặc đang dần xuất hiện, mà đại diện xuất chúng chính là Shakespeare, để thực hiện nhiệm vụ lịch sử "vung ngọn giáo náo động kịch trường shake-scene". Kịch trường ở đây có thể hiểu theo nghĩa rộng là bối cảnh xã hội, nơi đang hình thành những giá trị văn hóa mới gắn liền với những đại diện ưu tú của thời đại này. Như vậy, trên bình diện phân tâm học, kịch của Shakespeare cũng tạo ra những giá trị vô song mà có thể coi các giá trị này là các giá trị văn hóa điển hình cho thời đại Phục hưng.

Các tài năng văn chương thực thụ thường tái hiện hiện thực trong bối cảnh văn hóa rộng lớn, trong khuôn khổ không - thời gian nhiều chiều, tại đó cái bi cái hài lẫn lộn. Điển hình cho hình mẫu không - thời gian này chính là "bối cảnh Falstaff" với hình tượng đa diện đa chiều Falstaff. Một mặt, hắn là hiện thân của khoái lạc được thỏa mãn, mặt khác, hắn là hiệp sĩ tự bỏ nghề, sản phẩm tàn dư của một thời đã qua. Falstaff phủ định mọi khuôn khổ ràng buộc của luân lý quân quyền và thần quyền, đồng thời khẳng định bản chất con người là tự do trong mọi hành vi hay hoạt động. Falstaff mang sẵn 
trong mình năng khiếu hài hước, hắn nhìn tất cả với con mắt diễu cợt, khôi hài hoặc châm biếm. Hắn diễu cợt mọi người và diễu cợt cả bản thân hắn. Đây là một điều quan trọng trong văn hóa Phục hưng, tại đó nguyên tắc trần tục hóa cái thiêng liêng hóa và thiêng liêng hóa cái trần tục trở thành chuẩn mực ứng xử, trở thành mảnh đất ươm mầm tư tưởng cách mạng tiến bộ vì con người và cho con người. Nguyên tắc lên ngôi truất ngôi [1] này trở thành cơ chế của tiếng cười nhân văn thời đại Phục hưng, tiếng cười dân gian truyền thống của các lễ hội carnavale, tiếng cười tạo nên sức mạnh lạc quan và tính chiến đấu trong văn chương thời đại này. Tiếng cười gắn với nhân vật Falstaff trong kịch lịch sử sẽ được chuyển hóa vào các hài kịch ca ngợi tình yêu của Shakespeare, bởi lẽ chủ nghĩa nhân văn gắn liền với việc ca ngợi và cổ vũ cho tình yêu nam nữ, là một đặc trưng của nền văn hóa này. Các mối tình được miêu tả trong các hài kịch cũng như câu chuyện tình yêu trong bi kịch Romeo and Juliet là những chuyện tình cảm động, đầy ắp tình người, là kiểu tình yêu vượt lên mọi trở ngại, bất chấp thù hận dai dẳng. Các nhân vật yêu nhau một cách chân thành, trong trắng theo nguyên tắc "người với người sống để yêu nhau", họ sinh ra là để cho nhau, họ sinh ra là của nhau. Các mối tình đều mãnh liệt, sôi nổi như tinh thần Phục hưng và đều là tình yêu vượt ngưỡng, vượt qua mọi thử thách bởi khách quan hay chủ quan. Tình yêu là sự cảm thông của tấm lòng đối với tấm lòng, là sự kết nối con tim với con tim, là sự hòa điệu giữa tâm hồn và tâm hồn, là khát vọng được sống và được yêu... Tình yêu đó được đặt trong các thử thách đòi hỏi phải có trí tuệ để tường minh hay giải đáp: trong The Merchant of Venice, thử thách đối với Bassanio là việc tìm ra bí mật cất giấu ở một trong ba chiếc hòm bằng vàng, bằng bạc và bằng chì; còn trong The Comedy of Errors, A Midsummer Night's Dream, Twelfth Night... thì để tạo dựng tiếng cười, Shakespeare thường sử dụng biện pháp hiểu nhầm, hoặc gây hiểu nhầm bằng cặp song sinh giống nhau như lột, xây dựng kiểu tình yêu theo cặp định sẵn: chủ yêu chủ, tớ yêu tớ,... vốn rất hiếm gặp trong các sáng tạo văn chương. Khẳng định tình yêu chân thành trong trắng, khi các đôi nam nữ tự tìm đến nhau, tự nguyện xe đôi kết lứa cùng nhau, bình đẳng và hạnh phúc bên nhau, cũng chính là khẳng định cuộc sống, đồng thời qua đó cho thấy tình yêu không phải chỉ là quyền của đàn ông (droit de l'homme) mà còn là quyền của đàn bà (droit de la femme). Về phương diện này, Shakespeare là một trong những yếu nhân đầu tiên bênh vực chế độ nữ quyền.

Bốn trăm năm đã trôi qua, nhưng những tiếng cười, tiếng khóc, những niềm vui, những giọt nước mắt qua các vai kịch bản mà Shakespeare tạo ra vẫn còn sức sống mãnh liệt, khuấy đảo tâm can của mọi con người, khơi dậy trí tuệ thông thái cho mọi đối tượng. Mọi giá trị mà ông tạo ra đều thấm đẫm giá trị nhân văn Phục hưng, đều góp phần tạo ra giá trị văn hóa bênh vực và bảo vệ con người của thời đại này. Sức sống của các sáng tạo nghệ thuật mà Shakespeare để lại cũng chính là sức sống của thời đại Phục hưng, thời đại chuyển mình bước vào thời kì cận hiện đại của nhân loại.

\section{TÀI LIỆU THAM KHẢO}

1. Lê Nguyên Cẩn (2014), Tiếp cận văn học tù̀ góc nhìn văn hóa, Nxb Đại học Quốc gia, Hà Nội;

2. Driek Van Der Sterren (1996), Pshanaliza literaturii - Oedip Rege, Editura Trei;

3. Hài kịch Sêchxpia (1995), tập 1, Nxb Văn học, Hà Nội;

4. Tuyển tập kịch Sếcxpia (1995), Nxb Sân khấu, Hà Nội. 